\title{
Implementasi Penawaran Produk Toko Online KPRI UNS Dengan Metode AHP TOPSIS
}

Agus Purbayu, S.Si, M.Kom

Fakultas MIPA, Program Studi D3 Teknik Informatika

Universitas Sebelas Maret

Email: bayoe@mipa.uns.ac.id

\section{Amar Abdurrafi Nur, A.Md.}

Fakultas MIPA, Program Studi D3 Teknik Informatika Universitas Sebelas Maret

\section{Info Artikel}

Kata Kunci :

Toko Online,AHP, TOPSIS,

Sistem Informasi.

\section{Keywords :}

Online store,AHP,TOPSIS, Information system.

\section{Tanggal Artikel}

Dikirim : 20 Oktober 2018

Direvisi : 5 November 2018

Diterima : 15 November 2018

\section{Abstrak}

Toko online KPRI UNS Surakarta merupakan sebuah informasi berbasis web yang di gunakan untuk menjual barang-barang di toko KPRI UNS Surakarta. Sulitnya dalam penjualan barang dikarenakan tidak terdapat penawaran barang sesuai dengan kriteria. Sehingga dibutuhkan penawaran sesuai dengan kriteria anggota dengan metode AHP-TOPSIS.

Metode penelitian yang dilakukan untuk merancang dan membuat sistem informasi Toko Online KPRI UNS Surakrata ini adalah dengan menggunakan metode penelitian waterfall yaitu dengan pengumpulan data, melakukan analisa sistem (menentukan kebutuhan fungsional dan non fungsional), melakukan perancangan (ERD, use case diagram, use case text, sequence diagram, dan class diagram), dan implementasi (coding dan testing).

Hasil penelitian adalah sistem informasi toko online KPRI UNS Surakarta ini mampu untuk mengelola data dan kemudian menentukan penawaran yang ditentukan oleh sistem pembantu keputusan dengan metode AHP-Topsis.

\section{Abstarct}

Online store KPRI UNS Surakarta is a web-based information that is used to sell goods at the shop KPRI UNS Surakarta. Difficult in the sale of goods because there is no supply of goods in accordance with the criteria. So that the required in accordance with the criteria of members with AHP-TOPSIS method.

The metodology conducted to design and make information system online shop KPRI UNS Surakarta is used waterfall metodology is data collection, the system analysis(determine the functional and non functional requirement), system design (erd, use case diagram, use case text, sequence diagram, and class diagram), and implementation (coding and testing). Information system online shop

The results of this study are the KPRI UNS Surakarta online shop information system capable of managing data and then determining the bids determined by the decision support system using the AHP-Topsis method. 


\section{PENDAHULUAN}

Sistem Informasi Toko Online KPRI UNS Surakarta merupakan sebuah sistem informasi berbasis web yang digunakan untuk menjual barang-barang yang berada di toko KPRI UNS Surakarta. Sistem informasi ini memudahkan anggota KPRI untuk membeli barang-barang yang dibutuhkan secara online. Disamping itu admin dapat memberikan konfirmasi pemesanan yang dilakukan oleh anggota KPRI. Dalam kegiatan transaksi, pengolahan data transaksi yang sebelumnya secara manual, kini sudah dapat tersimpan dengan baik secara komputerisasi. Toko online yang merupakan kategori E-commerce yang menurut [3] mendefinisikan E-commerce dalam beberapa segi diantaranya :

"From a business process perspective, E-commerce is the use of technology to-wards the automation of business transactions and workflow. From a service perspective E-commerce is a tool that caters to the need of firms, consumers and management to cut down the transaction cost while improving the quality of goods/service and increasing the speed of delivery."

Dengan memahami pengertian diatas, maka $E$-commerce dapat diartikan dalam beberapa aspek, dua diantaranya adalah dari segi proses $E$-commerce adalah digunakan dalam memajukan teknologi bisnis transaksi dan alur kerja. Dari segi pelayanan E-commerce berarti alat yang digunakan untuk memenuhi kebutuhan perusahaan, konsumen dan manajemen untuk mengurangi biaya transaksi sekaligus meningkatkan kualitas barang atau jasa. Dengan adanya Sistem Informasi Toko Online KPRI UNS Surakarta ini, masih terdapat beberapa kendala yang dirasakan oleh admin dan anggota KPRI pada umumnya. Anggota KPRI belum menerima penawaran produk yang terdapat ditoko online ketika login. Selain dari sisi anggota KPRI, admin juga mempunyai beberapa kendala, yaitu tidak dapat memanfaatkan data-data yang dipunyai anggota untuk menawarkan produk-produk di toko online.

Berdasarkan permasalahan yang telah dipaparkan, maka dalam penelitian ini mengusulkan sebuah pengembangan terhadap sistem informasi tersebut, dengan judul "Implementasi Penawaran Product Toko Online KPRI UNS SURAKARTA Versi 2 dengan Penawaran Barang menggunakan Metode AHP Topsis". Menurut [6] Metode AHP merupakan salah satu metode yang dapat digunakan dalam sistem pengambilan keputusan dengan memperhatikan faktor-faktor persepsi, preferensi, pengalaman dan intuisi. AHP menggabungkan penilaian-penilaian dan nilai-nilai pribadi ke dalam satu cara yang logis. Untuk kepentingan pengambilan keputusan yang salah satunya untuk penawaran barang, sebagian besar pembuat keputusan dengan mempertimbangkan rasio manfaat/biaya, dihadapkan pada suatu keharusan untuk mengandalkan seperangkat sistem yang mampu memecahkan masalah secara efektif dan efisien, yang kemudian disebut Sistem Pendukung Keputusan [4]. Penyelesaian persoalan dengan AHP ada beberapa prinsip yaitu Penyusunan Hierarki, Comparative Judgement dan Penentuan Proiritas [2].

\section{METODE PENELITIAN}

Metode penelitian yang dilakukan pada penelitian ini menggunakan metode penelitian Waterfall terdiri dari beberapa tahap yaitu :

a. Tahap persiapan

Pada tahap ini dilakukan kajuan literatur seperti perumusan masalah dan penentuan tujuan penelitian.

b. Tahap Analisis

Pada tahap ini dilakukan analisis kebutuhan pengguna maupun sistem melalui survei lapangan sistem informasi toko online yang sudah ada.

c. Tahap perancangan

Pada tahap ini dilakukan perancangan struktur basisdata dan kebutuhan yang fungsionalitas sistem.

d. Tahap Implementasi

Pada tahap ini dilakukan implementasi sistem informasi pada bagian database, front end dan back end. Sistem yang dikembangkan dalam bentuk website.

e. Tahap pengujian

Pada tahap ini dilakukan pengujian desain dan pengujian fungsional yang bertujuan untuk menguji apakah implementasi sistem sudah sesuai dengan rancangan dan model sistem serta untuk menguji apakah sistem yang dikembangkan melakukan fungsi-fungsi yang bersesuaian dengan tujuan.

f. Tahap pelaporan

Tahap ini adalah tahap akhir yang terdiri dari kesimpulan, saran-saran, perbaikan dan pengembangan sistem serta penulisan laporan. 


\section{HASIL DAN PEMBAHASAN}

Langkah-langkah metode AHP adalah seperti berikut [1]:

1. Menyusun hirarki permasalahan yang dihadapi

2. Penilaian kriteria dan alternatif

Penilaian terhadap kriteria dan alternatif menggunakan perbandingan berpasangan dengan skala satu.

Perbandingan dilakukan oleh pihak yang menjadi pengambil keputusan. Apabila suatu elemen dibandingkan dengan dirinya sendiri maka nilainya 1 . Sedangkan jika elemen i dibandingkan dengan elemen j mendapatkan sebuah nilai, maka elemen j dibanding dengan nilai I, nilainya adalah kebalikannya.

3. Penentuan prioritas

Untuk setiap kriteria dan alternatif, dilakukan perbandingan berpasangan. Pertimbangan-pertimbangan terhadap perbandingan berpasangan diproses untuk memperoleh keseluruhan prioritas melalui tahapantahapan berikut:

a. Memberikan nilai setiap kriteria untuk mendapatkan nilai matriks berpasangan.

b. Membagi setiap nilai dengan total kolom yang bersangkutan, didapatkan normalisasi matriks.

c. Menjumlahkan nilai dari setiap baris dan membaginya dengan jumlah elemen didapatkan nilai prioritas.

4. Konsistensi logis

Perhitungan konsistensi logis mengikuti langkah-langkah berikut :

a. Mengalikan matriks dengan prioritas bersesuaian.

b. Menjumlahkan hasil perkalian-perkalian perbaris.

c. Hasil penjumlahan tiap baris dibagi prioritas bersangkutan dan hasilnya dijumlahkan.

d. Hasil dari perhitungan langkah $\mathrm{c}$ dibagi jumlah elemen, akan didapat $\lambda$ maks.

e. Indeks Konsistensi $(\mathrm{Cl})=(\lambda$ maks $-n)(n-1)$

f. $\quad$ Rasio konsistensi $=\mathrm{Cl} / \mathrm{CR}$

$\mathrm{RI}$ adalah indeks random konsistensi. Jika rasio konsistensi $\leq 0.1$, hasil perhitungan data dinyatakan benar.

Untuk menguji kebenaran sistem yang telah dibuat, maka akan dibandingkan dengan hasil perhitungan yang dilakukan sistem dengan hasil perhitungan manual. Dengan menggunakan 9 sampel data barang yang akan di tampilkan. Melakukan perhitungan manual untuk membandingkan hasil yang diperoleh dari sistem, dengan langkahlangkah sebagai berikut :

A. Langkah perhitungan

Melakukan perhitungan manual untuk membandingkan hasil yang diperoleh dari sistem, dengan langkahlangkah sebagai berikut :

1. Menentukan contoh penilaian untuk masing-masing kriteria yang sudah disusun oleh penulis, contoh penilaiannya dapat dilihat pada Tabel 1.

Tabel 1. Tabel pengujian sistem

\begin{tabular}{lll}
\hline Kriteria & Nama Kriteria & Contoh Penilaian \\
\hline K1 & Umur & 3 \\
\hline K2 & Unit Kerja & 9 \\
\hline K3 & Jenis kelamin & 7 \\
\hline K4 & Banyak Pesanan & 1 \\
\hline
\end{tabular}

Nilai untuk masing-masing kriteria telah disesuaikan dengan tingkat kepentingan antara kriteria yang dibandingkan dengan menggunakan acuan skala penilaian perbandingan berpasangan.

2. Menentukan perbandingan nilai kepentingan (Preferensi)

Matriks ini diperoleh dengan rumus, nilai tiap sel dibagi dengan tiap-tiap sel dalam 1 baris dilakukan ke semua kolom. Hasil perhitungan nilai kepentingan dapat di lihat pada Tabel 2, dan rumusnya berada pada persamaan

$$
a_{i j}=w_{i} / w_{j}
$$


Tabel 2. Tabel perbandingan nilai kepentingan (preferensi)

Matrik perbandingan nilai kepentingan (preferensi)

\begin{tabular}{lllll}
\hline & K1 & K2 & K3 & K4 \\
\hline K1 & 1 & 0,333333 & 0,428571429 & 3 \\
\hline K2 & 3 & 1 & 1,285714286 & 9 \\
\hline K3 & 2,333333333 & 0,777777778 & 1 & 7 \\
\hline K4 & 0,333333333 & 0,111111111 & 0,142857143 & 1 \\
\hline
\end{tabular}

3. Menjumlahkan tiap kolom dari tabel perandingan nilai kepentingan(preferensi).

Hasil dari penjumlahan tabel perbandingan nilai kepentingan dapat dilihat pada Tabel 3.

Tabel 3. Tabel hasil penjumlahan nilai kepentingan (preferensi)

Jumlah Tiap Kolom

\begin{tabular}{llll}
\hline K1 & K2 & K3 & K4 \\
\hline 6,6666666667 & 2,222222222 & 2,857142857 & 20
\end{tabular}

4. Menghitung nilai normalisasi dari matrix perbandingan nilai kepentingan (preferensi).

Matrix ini diperoleh dengan rumus, jumlah dari tiap kolom dibagi dengan masing-masih sel pada satu baris dan satu kolom. Hasil dari nilai normalisasi dapat dilihat pada Tabel 4, dan rumus normalisasinya berada pada persamaan

$$
w_{j}=\frac{w_{j}}{\sum w_{j}}
$$

Tabel 4. Tabel nilai normalisasi

Matrik Normalisasi

\begin{tabular}{llllll}
\hline & K1 & K2 & K3 & K4 & Jumlah \\
\hline K1 & 0,15 & 0,15 & 0,15 & 0,15 & 0,6 \\
\hline K2 & 0,45 & 0,45 & 0,45 & 0,45 & 1,8 \\
\hline K3 & 0,35 & 0,35 & 0,35 & 0,35 & 1,4 \\
\hline K4 & 0,05 & 0,05 & 0,05 & 0,05 & 0,2
\end{tabular}

5. Menghitung nilai eigen vektor

Nilai ini dihitung dengan rumus, kolom jumlah dari matrix normalisasi dibagi dengan 4 ( banyaknya kriteria yang akan dihitung ). Hasil dari perhitungan nilai eigen vektor dapat dilihat pada Tabel 5.

Tabel 5. Tabel nilai eigen vektor

\begin{tabular}{llll} 
Eigen Vektor & & \\
\hline K1 & K2 & K3 & K4 \\
\hline 0,15 & 0,45 & 0,35 & 0,05
\end{tabular}

6. Menghitung Rasio konsistensi (CR)

Perhitungan ini digunakan untuk memastikan bahwa nilai rasio konsistensi $(C R)<0,1$, jika ternyata nilai $C R$ lebih besar dari 0,1. Maka matriks perbandingan harus diperbaiki. Untuk menghitung rasio konsistensi, dilakukan dengan langkah sebagai berikut:

a) Menentukan nilai eigen max ( ${ }^{*}$ elemen jumlah di bagi dengan elemen eigen vektor lalu di jumlah)

Maka hasil Eigen Max = 16 dibagi dengan 4 maka hasilnya adalah 4

b) Menghitung index konsistensi $(\mathrm{Cl})$ 
Yaitu dengan cara pengurangan jumlah kriteria dengan hasil dari nilai eigen max dibagi dengan hasil eigen max di kurangi 1.

Maka hasil $\mathrm{Cl}=0$

c) Menghitung Rasio Konsistensi (CR)

Yaitu dengan cara $\mathrm{Cl} / \mathrm{RI}$

$\mathrm{CR}=0 / 1,24$ maka hasilnya adalah 0

Karena nilai $\mathrm{CR}<0,1$ berarti preferensi pembobotan adalah konsisten dan dapat digunakan sebagai bobot untuk perhitungan topsis.

7. Menentukan 9 sampel data dengan mengacu pada 4 kriteria yang telah di tentukan. Data kriteria dapat dilihat pada Tabel 6 .

Tabel 6. Tabel contoh sampel data berdasarkan kriteria

id_barang Umur Unit Kerja Jenis Kelamin Banyak Pesanan

\begin{tabular}{lllll}
\hline 1 & 75 & 75 & 100 & 50 \\
\hline 2 & 50 & 75 & 50 & 100 \\
\hline 3 & 75 & 50 & 100 & 100 \\
\hline 4 & 50 & 75 & 50 & 25 \\
\hline 5 & 50 & 75 & 50 & 100 \\
\hline 7 & 100 & 75 & 100 & 100 \\
\hline 8 & 100 & 75 & 50 & 75 \\
\hline 9 & 25 & 75 & 50 & 100 \\
\hline
\end{tabular}

8. Menghitung perpangkatan tiap-tiap sel berdasarkan kriteria

Kemudian setelah dipangkatkan maka dihitung nilai akar dari jumlah hasil perpangkatan tiap-tiap baris. Hasil dari perpangkatan dan akarnya dapat dilihat pada Tabel 7.

Tabel 7. Tabel hasil perpangkatan dan hasil akar.

\begin{tabular}{lllll} 
Id_barang & K1 & K2 & K3 & K4 \\
\hline 1 & 5625 & 5625 & 10000 & 2500 \\
\hline 2 & 2500 & 5625 & 2500 & 10000 \\
\hline 3 & 5625 & 2500 & 10000 & 10000 \\
\hline 4 & 2500 & 5625 & 2500 & 625 \\
\hline 5 & 2500 & 5625 & 2500 & 10000 \\
\hline 6 & 10000 & 5625 & 10000 & 10000 \\
\hline 7 & 10000 & 5625 & 2500 & 5625 \\
\hline 9 & 625 & 5625 & 2500 & 10000 \\
\hline Jumlah & 10000 & 10000 & 10000 & 5625 \\
\hline Akar & $\mathbf{4 9 3 7 5}$ & $\mathbf{5 1 8 7 5}$ & $\mathbf{5 2 5 0 0}$ & $\mathbf{6 4 3 7 5}$ \\
\hline
\end{tabular}

9. Menghitung nilai matrix keputusan yang ternormalisasi

Nilai ini dihitung dengan rumus, sel akar masing-masing kriteria dibagi dengan tiap sel dalam 1 kolom kriteria. Hasil dari perhitungan nilai matrix keputusan dapat dilihat pada persamaan 


$$
r_{i j}=\frac{x_{i j}}{\sum_{i=1}^{n} x_{i j}^{2}}
$$

Tabel 8. Tabel nilai matriks keputusan yang ternormalisasi.

\begin{tabular}{lllll} 
Id_barang & K1 & K2 & K3 & K4 \\
\hline 1 & 0,33752637 & 0,32929278 & 0,43643578 & 0,197065856 \\
\hline 2 & 0,22501758 & 0,32929278 & 0,21821789 & 0,394131711 \\
\hline 3 & 0,33752637 & 0,21952852 & 0,43643578 & 0,394131711 \\
\hline 4 & 0,22501758 & 0,32929278 & 0,21821789 & 0,098532928 \\
\hline 6 & 0,22501758 & 0,32929278 & 0,21821789 & 0,394131711 \\
\hline 7 & 0,45003516 & 0,32929278 & 0,43643578 & 0,394131711 \\
\hline 8 & 0,45003516 & 0,32929278 & 0,21821789 & 0,295598783 \\
\hline 9 & 0,11250879 & 0,32929278 & 0,21821789 & 0,394131711 \\
\hline & 0,45003516 & 0,43905704 & 0,43643578 & 0,295598783
\end{tabular}

10. Menghitung nilai matriks keputusan normalisasi berbobot

Nilai ini dihitung dengan rumus, tiap-tiap sel dipangkatkan. Hasil dari perhitungan nilai matriks keputusan normalisasi berbobot adalah dapat dilihat pada Tabel 9 .

Tabel 9. Tabel nilai matriks keputusan normalisasi berbobot

\begin{tabular}{lllll} 
id_barang & K1 & K2 & K3 & K4 \\
\hline 1 & 0,050628956 & 0,148181751 & 0,152752523 & 0,009853293 \\
\hline 2 & 0,033752637 & 0,148181751 & 0,076376262 & 0,019706586 \\
\hline 3 & 0,050628956 & 0,098787834 & 0,152752523 & 0,019706586 \\
\hline 4 & 0,033752637 & 0,148181751 & 0,076376262 & 0,004926646 \\
\hline 6 & 0,033752637 & 0,148181751 & 0,076376262 & 0,019706586 \\
\hline 7 & 0,067505274 & 0,148181751 & 0,152752523 & 0,019706586 \\
\hline 8 & 0,067505274 & 0,148181751 & 0,076376262 & 0,014779939 \\
\hline
\end{tabular}

11. Tabel ideal positif negatif tiap-tiap kriteria yang disusun oleh penulis, daftar tabel ideal positif negatif dapat dilihat pada Tabel 10.

Tabel 10. Tabel ideal positif negative

\begin{tabular}{ll} 
Nama Kriteria & Status \\
\hline Umur & Negatif \\
\hline Unit Kerja & Positif \\
\hline Jenis Kelamin & Positif \\
\hline Jumlah Pemesanan & Negatif \\
\hline
\end{tabular}

Nilai positif maksudnya adalah benefit kriteria. Jika semakin tinggi nilai dari kriteria tersebut maka semakin baik. Sedangkan nilai negatif maksudnya adalah cost kriteria. Jika semakin kecil nilai dari kriteria tersebut maka semakin baik.

12. Menentukan nilai tabel solusi ideal positif dan negatif 
Nilai ini dihitung dengan rumus, nilai minimal dari tabel nilai matrix keputusan normalisasi berbobot. Tabel solusi ideal positif dan negatif dapat dilihat pada Tabel 11, sedangkan rumus nilai solusi ideal positif dan solusi ideal negatif berada pada persamaan

$$
\begin{aligned}
& A^{+}=\left\{\left(\max v_{i j} \mid j \in J\right),\left(\min v_{i j} \mid j \in J^{\prime}\right), i=1,2,3, \ldots, m\right\} \\
& =\left\{v_{1}^{+}, v_{2}^{+}, v_{3}^{+}, \ldots \ldots, v_{m}^{+}\right\} \\
& A^{-}=\left\{\left(\min v_{i j} \mid j \in J\right),\left(\max v_{i j} \mid j \in J^{\prime}\right), i=1,2,3, \ldots, m\right\} \\
& =\left\{v_{1}^{-}, v_{2}^{-}, v_{3}^{-}, \ldots \ldots, v_{m}^{-}\right\}
\end{aligned}
$$

Tabel 11. Tabel nilai solusi ideal positif dan negatif

\begin{tabular}{lllll} 
& K1 & K2 & K3 & K4 \\
\hline Y+ & 0,016876319 & 0,197575668 & 0,152752523 & 0,004926646 \\
\hline Y- & 0,067505274 & 0,098787834 & 0,076376262 & 0,019706586
\end{tabular}

13. Menentukan matriks nilai tabel solusi ideal positif normalisasi berbobot

Nilai ini dihitung dengan rumus, pengurangan pada baris $Y+$ dengan tiap-tiap sel pada Table 12 nilai matriks keputusan normalisasi berbobot.

Tabel 3.Tabel nilai solusi ideal positif normalisasi berbobot

\begin{tabular}{lllll} 
Id_barang & K1 & K2 & K3 & K4 \\
\hline 1 & $-0,033752637$ & $-0,049393917$ & $-0,076376262$ & $-0,004926646$ \\
\hline 2 & $-0,016876319$ & $-0,049393917$ & 0 & $-0,014779939$ \\
\hline 3 & $-0,033752637$ & 0 & $-0,076376262$ & $-0,014779939$ \\
\hline 4 & $-0,016876319$ & $-0,049393917$ & 0 & 0 \\
\hline 5 & $-0,016876319$ & $-0,049393917$ & 0 & $-0,014779939$ \\
\hline 6 & $-0,050628956$ & $-0,049393917$ & $-0,076376262$ & $-0,014779939$ \\
\hline 7 & $-0,050628956$ & $-0,049393917$ & 0 & $-0,009853293$ \\
\hline 8 & 0 & $-0,049393917$ & 0 & $-0,014779939$ \\
\hline 9 & $-0,050628956$ & $-0,098787834$ & $-0,076376262$ & $-0,009853293$
\end{tabular}

14. Menentukan nilai kuadrat dari tabel nilai solusi ideal positif

Nilai ini dihitung dengan rumus, perkalian pada tiap-tiap sel pada tabel nilai solusi ideal positif. Hasil dari nilai kuadratnya adalah seperti pada Tabel 13:

Tabel 12. Tabel nilai kuadrat dari tabel nilai solusi ideal positif

\begin{tabular}{llllll} 
ID_barang & K1 & K2 & K3 & K4 & JUMLAH \\
\hline 1 & 0,001139241 & 0,002439759 & 0,005833333 & $2,42718 \mathrm{E}-05$ & $\mathbf{0 , 0 0 9 4 3 6 6 0 5}$ \\
\hline 2 & 0,00028481 & 0,002439759 & 0 & 0,000218447 & $\mathbf{0 , 0 0 2 9 4 3 0 1 6}$ \\
\hline 3 & 0,001139241 & 0 & 0,005833333 & 0,000218447 & $\mathbf{0 , 0 0 7 1 9 1 0 2}$ \\
\hline 4 & 0,00028481 & 0,002439759 & 0 & 0 & $\mathbf{0 , 0 0 2 7 2 4 5 6 9}$ \\
\hline 5 & 0,00028481 & 0,002439759 & 0 & 0,000218447 & $\mathbf{0 , 0 0 2 9 4 3 0 1 6}$ \\
\hline 6 & 0,002563291 & 0,002439759 & 0,005833333 & 0,000218447 & $\mathbf{0 , 0 1 1 0 5 4 8 3}$ \\
\hline 7 & 0,002563291 & 0,002439759 & 0 & $9,70874 \mathrm{E}-05$ & $\mathbf{0 , 0 0 5 1 0 0 1 3 8}$ \\
\hline 8 & 0 & 0,002439759 & 0 & 0,000218447 & $\mathbf{0 , 0 0 2 6 5 8 2 0 6}$ \\
\hline 9 & 0,002563291 & 0,009759036 & 0,005833333 & $9,70874 \mathrm{E}-05$ & $\mathbf{0 , 0 1 8 2 5 2 7 4 8}$
\end{tabular}

15. Hasil dari nilai solusi ideal positif 
Nilai ini didapat dari rumus, akar dari jumlah yang berada di tabel nilai kuadrat dari nilai solusi ideal positif. Hasil nilai solusi ideal positif dilihat pada tabel 3.14. sedangkan rumus nilai sulusi ideal positif dan negatif seperti pada persamaan berikut

$$
\begin{aligned}
& S i_{i}^{+}=\sqrt{\sum_{j=1}^{n}\left(v_{i j}-v_{1}^{+}\right)^{2}}, \text { dengan } i=1,2,3, \ldots . m \\
& S i_{i}^{-}=\sqrt{\sum_{j=1}^{n}\left(v_{i j}-v_{1}^{-}\right)^{2}}, \text { dengan } i=1,2,3, \ldots . m
\end{aligned}
$$

Tabel 13. Tabel nilai solusi ideal positif ID_BARANG

\begin{tabular}{ll}
\hline 1 & 0,097142188 \\
\hline 2 & 0,054249569 \\
\hline 3 & 0,084799885 \\
\hline 4 & 0,052197406 \\
\hline 5 & 0,054249569 \\
\hline 6 & 0,105141952 \\
\hline 7 & 0,071415247 \\
\hline 8 & 0,051557789 \\
\hline 9 & 0,135102731
\end{tabular}

16. Menentukan matriks nilai tabel solusi ideal negatif normalisasi berbobot.

Nilai ini dihitung dengan rumus, pengurangan pada baris $Y$ - dengan tiap-tiap sel pada tabel nilai matriks keputusan normalisasi berbobot. Hasil dari nilai solusi ideal negatif dapat dilihat pada Tabel 15.

Tabel 14. Tabel nilai solusi ideal negatif normalisasi berbobot

\begin{tabular}{lllll} 
id_barang & K1 & K2 & K3 & K4 \\
\hline 1 & 0,016876319 & 0,049393917 & 0 & 0,009853293 \\
\hline 2 & 0,033752637 & 0,049393917 & 0,076376262 & 0 \\
\hline 3 & 0,016876319 & 0,098787834 & 0 & 0 \\
\hline 4 & 0,033752637 & 0,049393917 & 0,076376262 & 0,014779939 \\
\hline 6 & 0,033752637 & 0,049393917 & 0,076376262 & 0 \\
\hline 7 & 0 & 0,049393917 & 0 & 0 \\
\hline 8 & 0 & 0,049393917 & 0,076376262 & 0,004926646 \\
\hline 9 & 0,050628956 & 0,049393917 & 0,076376262 & 0 \\
\hline & 0 & 0 & 0 & 0,004926646
\end{tabular}

17. Menentukan nilai kuadrat dari tabel nilai solusi ideal negatif

Nilai ini dihitung dengan rumus, perkalian pada tiap-tiap sel pada tabel nilai solusi ideal negatif. Hasil dari nilai kuadratnya dapat dilihat pada Tabel 16 : 
Tabel 15. Tabel nilai kuadrat dari tabel nilai solusi ideal negative

\begin{tabular}{llllll} 
Id_barang & K1 & K2 & K3 & K4 & JUMLAH \\
\hline 1 & 0 & 0,006870957 & 0 & 0,000434397 & 0,007305354 \\
\hline 2 & 0,015340909 & 0,001626143 & 0 & $7,97872 \mathrm{E}-05$ & 0,01704684 \\
\hline 3 & 0 & 0,006870957 & 0 & 0,000221631 & 0,007092588 \\
\hline 4 & 0,005522727 & 0,000607294 & 0,006805556 & 0,000221631 & 0,013157208 \\
\hline 5 & 0,030068182 & 0 & 0 & 0 & 0,030068182 \\
\hline 6 & 0,030068182 & $8,03034 \mathrm{E}-05$ & 0 & 0 & 0,030148485 \\
\hline 7 & 0,005522727 & 0,000607294 & 0 & 0,000221631 & 0,006351653 \\
\hline 8 & 0,005522727 & 0,000607294 & 0,006805556 & 0,000221631 & 0,013157208 \\
\hline 9 & 0,005522727 & 0,000607294 & 0,006805556 & 0,000221631 & 0,013157208 \\
\hline
\end{tabular}

18. Hasil dari nilai solusi ideal negatif

Nilai ini didapat dari rumus, akar dari jumlah yang berada di tabel nilai kuadrat dari nilai solusi ideal negatif. Hasil dari solusi ideal negatif berada pada Tabel 17.

Tabel 16. Tabel nilai solusi ideal negatif

\begin{tabular}{ll} 
id_barang & \\
\hline 1 & 0,053119267 \\
\hline 2 & 0,097017178 \\
\hline 3 & 0,100218992 \\
\hline 4 & 0,098136535 \\
\hline 5 & 0,097017178 \\
\hline 6 & 0,049393917 \\
\hline 7 & 0,091089869 \\
\hline 8 & 0,104097952 \\
\hline 9 & 0,004926646 \\
\hline
\end{tabular}

19. Kedekatan terhadap solusi ideal positif

Nilai ini didapat dari rumus, sel dari ideal negatif dibagi dengan penjumlahan antara sel idel negatif dengan sel ideal positif. Hasil perhitungannya dapat dilihat pada Tabel 18 , sedangkan rumus nilai kedekatan terhadap solusi ideal positif adalah

$$
C_{i *}=\frac{s_{i-}}{s_{i *}+S_{i-}} \text {, dengan } 0<C_{i *}<1 \text { dan } i=1,2,3, \ldots, m
$$

Tabel 17. Tabel kedekatan terhadap solusi ideal positif

\begin{tabular}{ll} 
id_barang & \\
\hline 1 & 0,353512263 \\
\hline 2 & 0,641364873 \\
\hline 3 & 0,54166901 \\
\hline 4 & 0,652790278
\end{tabular}




\begin{tabular}{ll}
5 & 0,641364873 \\
\hline 6 & 0,319627522 \\
\hline 7 & 0,560535391 \\
\hline 8 & 0,668770397 \\
\hline 9 & 0,035182949
\end{tabular}

20. Hasil Akhir dari Perhitungan AHP TOPSIS

Hasil ini didapat dari mengurutkan dari nilai terkecil ke yang terbesar berdasarkan tabel kedekatan terhadap solusi positif. Hasil akhir dari perhitungan AHP TOPSIS adalah seperti pada Tabel 19 :

Tabel 18. Tabel Hasil Akhir perhitungan AHP Topsis

RANKING

\begin{tabular}{ll}
\hline 2 & 0,668770397 \\
\hline 6 & 0,652790278 \\
\hline 8 & 0,641364873 \\
\hline 5 & 0,641364873 \\
\hline 3 & 0,560535391 \\
\hline 7 & 0,54166901 \\
\hline 9 & 0,353512263 \\
\hline 4 & 0,319627522 \\
\hline 1 & 0,035182949
\end{tabular}

\section{KESIMPULAN}

Berdasarkan pembahasan sistem yang telah di paparkan, dapat disimpulkan bahwa :

1. Sistem ini dikembangkan menggunakan bahasa pemrograman PHP dengan framework Codeigniter dan database MySQL.

2. Dengan menggunakan pengujian black box terhadap poin fungsionalitas maka hasil implementasi sudah sesuai dengan perancangan fungsionalitas sistem.

3. Perhitungan AHP TOPSIS berhasil dilakukan tanpa error dan menghasilkan perhitungan akhir perangkingan barang yang ditawarkan.

\section{DAFTAR PUSTAKA}

[1] Bohlooli \& Chakherlouy., 2014. Decision Support System Validation Recipient Program Using AHPTOPSIS Method. Di akses 24 Juli 2017, http://docplayer.info/48834175-Decision-support-system-validation-recipientprogram-keluarga-harapan-pkh-in-wonosari-district-using-ahptopsis-method.html

[2] Hartono, E. et al. 2013. Sistem Pendukung Keputusan (SPK) pemilihan karyawan Terbaik Menggunakan Metode AHP. Di akses 24 Juli 2017, http://jurnal.uii.ac.id/index.php/Snati/article/view/2646/2424

[3] Kalakota, R and Whinston, A.B. 1997. Electronic Commerce: A Manager's. Guide. New Jersey: Addison-Wesley Professional. Jakarta: Elex Media Komputindo.

[4] Suryadi, K., Ramdhani, M. A., 1998, Sistem Pendukung Keputusan, Bandung : Remaja Rosdakarya.

[5] Suryadi, K., Ramdhani, M. A., 2002, Sistem Pendukung Keputusan: Suatu Wacana Struktural Idealisasi dan Implementasi Konsep Pengambilan Keputusan, Bandung : Remaja Rosdakarya

[6] Thomas L. Saaty. McGraw-Hill, 1980 The Analytic Hierarchy Process: Planning, Priority Setting, Resource Allocation. 